\section{Carotenoids of the Chicken Retina}

THE cones of many bird and reptile retinas contain brilliantly coloured oil globules. In the chicken they are red, golden and yellow-green ${ }^{1,2}$. They possess considerable interest, for light must filter through them to enter the sensitive cone outer limbs, and they may serve, therefore, as a mechanism for colour vision ${ }^{3}$.

Kühne and Ayres $^{2}$ effected a crude separation of chicken retinal pigments into three fractions: purplish red "rhodophane", golden or orange "xenthophane", and yellow-green "chlorophane".

We have crystallized three such pigments from retinal extracts. They are carotenoids, and in suitable solvents reproduce closely the colours of the retinal droplets :

(1) The purplish red pigment, astacene. Epiphasic when shaken with benzine and 90 per cent methanol. Soluble in concentrated caustic potash ; precipitates as a red soap on dilution with water. Crystallizes from methanol-acetic acid in thin, curved, purple blades; from pyridine in fine needles. Crystals insoluble in benzine, almost insoluble in methanol, readily soluble in pyridine. The spectrum consists of a single broad band, maximal at $477 \mathrm{m \mu}$ in hexane (Fig. I a), at $499.5 \mathrm{~m} \mu$ in pyridine, at $497 \mathrm{~m} \mu^{\circ}$ in castor oil (used to simulate the retinal oil).

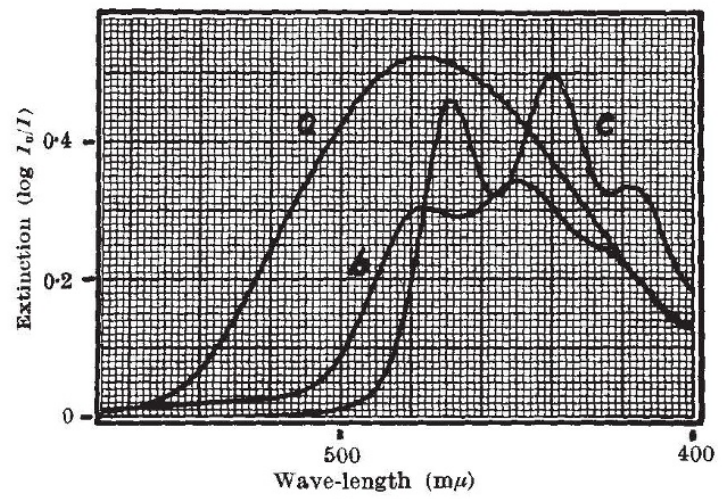

Fig. 1.

(2) A golden or orange xanthophyll. Shaken with benzine and 90 per cent methanol, it is epiphasic before and hypophasic after saponification. This is the typical behaviour of xanthophyll esters. Crystals from methanol solution are orange-red in colour, practically insoluble in benzine, readily soluble in methanol. The spectrum possesses three bands, at (421), 449.5 and $478 \mathrm{m \mu}$ in hexane (Fig. $1 \mathrm{~b}$ ), and at (430), 463 and $490 \mathrm{~m} \mu$ in castor oil. This is close to the spectrum of lutein $(447.5$ and $477.5 \mathrm{~m} \mu$ in benzine).

(3) A yellow or yellow-green hydrocarbon. Epiphasic when shaken with benzine and 90-95 per cent mothanol. Crystals from methanol solution are russet in colour, almost completely insoluble in methanol, readily soluble in hexane. The spectrum possesses three sharp maxima, at 418,440 and $469.5 \mathrm{mu}$ in hexane (Fig. $1 \mathrm{c}$ ), and at 428, 450 and $480.5 \mathrm{~m} \mu$ in castor oil. This spectrum lies at much lower wave-lengths than that of any known carotene except sarcinene $(415,440,469 \mathrm{~m} \mu)^{4}$.

It seems clear from the appearance of the cone globules that one of these pigments predominates in each of them. The fact that one pigment is acidic, one an alcohol and one a hydrocarbon greatly aids their separation in vitro. A precisely similar situation is found in the retina of the turtle, Clemmys insculpta $a^{5}$. Possibly this chemical differentiation is the basis also of pigment segregation in vivo.

Astacene apparently is synthesized by the chicken. We found no trace of it in chicken livers or serum. Though none could be found in the egg yolk, red cone droplets appeared in our chick embryos on the nineteenth day of incubation $\left(37^{\circ} \mathrm{C}\right.$.). The hydrocarbon pigment also may be synthesized in situ, for it has not been identified either in the egg or in the customary chicken diet.

If the chicken depends upon these pigments for colour discrimination, it should fail to differentiate monochromatic lights between about $600 \mathrm{m \mu}$ and $700 \mathrm{~m} \mu$, for none of the pigments in castor oil absorbs appreciably in this region. It is significant that the pigeon, which possesses a similar system of cone droplets, is unable to discriminate hue differences between 615 and $700 \mathrm{~m} \mu^{6}$.

\section{Biological Laboratories, \\ George WaLd. HYMAN ZUSSMAN.}

Harvard University,

Cambridge, Massachusetts.

$$
\text { June } 25 .
$$

I Hannover, A., Arch. Anat., 314 (1843) ; colour plate in Hess, C., "Hdbch. vergl. Physiol.", 4, 555 (1913).

${ }^{2}$ Kühne, W., and Ayres, W. C., Onters. physiol. Inst. Heidelberg, 1, 341 (1878); J. Physiol., 1, iog (1878-79).

schultze, M., Arch. mikr. Anat., 2, 175 (1866); Roaf, H. E. Physiol. Rev., 13, 43 (1933).

- Chargaff, E., Naturwiss., 20, 872 (1932).

- Wald, G., unpublished observations.

Bamiton, W. F., and Coleman, T. B., J. Comp. Psych., 15, 183 (1933).

\section{Position of Maximum Optical Sensitivity of Sensitized Photographic Plates}

IN one of the first papers ${ }^{1}$ on the phenomenon of sensitization of photographic plates to the long-wave rays of the spectrum by dyestuffs, Vogel noted that the maximum sensitivity is often shifted by several hundred Angstrom units towards the red in comparison with the maximum absorption of the dyestuffs in solution. The usually accepted explanation ${ }^{2}$ of this phenomenon is that it is due to the displacement of the maximum of absorption of the dyestuff by its adsorption on the silver halide. But on account of the difficulties connected with measuring the absorption by scattering media, this hypothesis has not yet been confirmed experimentally.

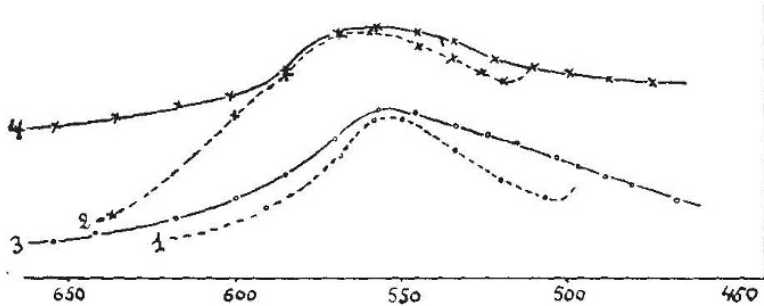

Posimions of Maxima Optical Sensitivity Fig. 1.

With the aid of the König-Martens spectrophotometer, we have obtained absorption curves of erythrosin and phloxine sensitizers adsorbed on transparent layers of silver bromide sublimated in vacuum. They were prepared by a method analogous to the method of de Boer ${ }^{3}$ as described in a series of papers by him on the adsorption of dyestuffs on sublimated layers of alkali earth metals. 